\title{
Phylloplane fungi in Hong Kong mangroves: evaluation of study methods
}

\author{
Olive H. K. Lee \\ Kevin D. Hyde ${ }^{1}$ \\ Centre for Research in Fungal Diversity, Department of \\ Ecology E Biodiversity, The University of Hong Kong, \\ Pokfulam Road, Hong Kong
}

\begin{abstract}
Many methods have been used to study phylloplane fungi, most of which have constraints and may result in biased results. This study used light microscopy and scanning electron microscopy (SEM) to investigate fungal abundance on the leaves of the most common mangrove trees in Hong Kong, Kandelia candel and Aegiceras corniculatum. Species richness was investigated using light microscopy and a leaf washing method. Methods to study phylloplane fungi are discussed and the performances of these three investigation methods are evaluated. Seven mitosporic fungal taxa were found by light microscopy, while 30 sporulating taxa and 18 Mycelia sterilia were isolated using the leaf washing method. Fungal abundance in terms of percentage cover investigated with light microscopy was similar using the SEM method, and was significantly higher on Aegiceras corniculatum than on Kandelia candel. Fungal abundance peaked in the summer and was lowest in the winter. This study indicates that light microscopy reveals the most typical phylloplane fungi and is more efficient than SEM, while the leaf washing method reveals many casual species and is not quantitative.
\end{abstract}

Key Words: abundance, Aegiceras corniculatum, Kandelia candel, species richness, temporal variation

\section{INTRODUCTION}

Phylloplane fungi are the mycota growing on the surfaces of leaves (Langvad 1980). There are two groups of phylloplane fungi; residents and casuals (Norse 1972). Residents can multiply on the surface of healthy leaves without noticeably affecting the host whereas casuals land on the leaf surface but cannot grow (Leben 1965). Phylloplane fungi have been poorly studied as compared to endophytes, saprobes and pathogenic fungi. Most phylloplane fungal stud-

Accepted for publication December 25, 2001.

${ }^{1}$ Corresponding author, Email: kdhyde@hkucc.hku.hk ies have been concerned with pathogens or non-parasitic fungi of crops or economically-important trees (e.g., Dickinson 1967, 1973, Pugh and Williams 1968, Lamb and Brown 1970, Pugh and Mulder 1971, Bainbridge and Dickinson 1972, Norse 1972, Godfrey 1974, Mishra and Dickinson 1981, Cabral 1985, Vardavakis 1988, Carris 1992). There have been some studies on the phylloplane fungi of mangroves (e.g., Kuthubutheen 1981, 1984, Sivakumar and Kathiresan 1990, Goh and Yipp 1996). Several methods are available to study phylloplane fungi (see review by Lindsey 1976). The most common methods, discussed below, include direct observation by light microscopy, impression films, observation with scanning electron microscopy (SEM), plating of leaves, incubation in damp chambers and leaf impression and tape impression for culturing fungi.

The number of fungal colonies and the percentage cover of phylloplane fungi can be estimated by direct observation using light microscopy (Lamb and Brown 1970, Ruscoe 1971, Vardavakis 1988) or scanning electron microscopy (Mishra and Dickinson 1981). Observations under light microscopes can be enhanced with the use of different kinds of impression film such as clear nail polish (Dickinson 1967, Bainbridge and Dickinson 1972), Scotch tape (Cunningham 1972, Langvad 1980), cellulose nitrate (Mishra and Dickinson 1981) and cellulose acetate (Dickinson et al 1974).

Fungal species richness can also be studied by leaf impression (Lamb and Brown 1970, Bainbridge and Dickinson 1972) and leaf washing methods (Dickinson 1967, 1973, Hislop and Cox 1969, Bainbridge and Dickinson 1972, Kuthubutheen 1981, Mishra and Dickinson 1981). Leaf impression is made by pressing leaf surfaces against agar in Petri dishes to produce leaf-imprints. The leaves are then discarded and the plates are incubated at room temperature until colonies grow on the agar surface. Plating of leaf washing aliquots has been one of the most popular methods used to study phylloplane fungi. Leaf disks are cut and shaken in sterile water in a reciprocating shaker and a dilution series prepared from the water. The aliquots are then plated onto agar and examined over several days' of incubation.

Plating of the washed disks have also been used to study fungal species richness on leaves (Dickinson 
1967, 1973, Ruscoe 1971, Bainbridge and Dickinson 1972, Godfrey 1974, Kuthubutheen 1981, Mishra and Dickinson 1981, Vardavakis 1988). Leaf disks are shaken in sterile water with detergents to remove fungal propagules. The washed disks are blotted dry and plated on agar plates which are then incubated and examined until no further colonies are encountered. Damp chambers can also used to incubate the washed leaf disks (Dickinson 1967, Ruscoe 1971, Bainbridge and Dickinson 1972, Kuthubutheen 1981, Mishra and Dickinson 1981, Vardavakis 1988). The washed disks are placed on sterile, moist, filter paper in a Petri dish before further investigation.

There are several other methods for investigating phylloplane fungi such as tape impressions followed by culturing (Langvad 1980) and spore-fall techniques (Lamb and Brown 1970, Dickinson 1973, Langvad 1980, Vardavakis 1988). With tape impressions a thin agar film is pressed onto the leaf surface that can then be incubated in Petri dishes containing filter paper moistened with glycerol. The spore-fall technique involves attaching the leaf onto the inside of the Petri dish lid above agar, using the premise that fungal spores can fall or are shot onto the agar surface.

Most of the methods mentioned above used in the study of phylloplane fungi have advantages and disadvantages. Direct observation, for example, enables one to determine the distribution of the phylloplane population and provides useful information such as the growth forms and spatial distributions of a variety of microorganisms. Direct microscopy gives a more precise estimate of population size than plate counting methods (Baker 1981). Direct count methods give higher population densities than impressions because some organisms may remain on the plant when the adhesive tape is removed. It is not, however, easy to determine the viability and identity of propagules unless the groups are separated by their morphological differences using microscopy (Last and Warren 1972, Baker 1981, Parbery et al 1981). The irregular nature of the plant surface, moreover, makes examination difficult at high magnification (Paton 1982).

Leaf washing facilitates the identification of 'colonizers', but cannot separate the true colonizers from chance itinerants (Last and Warren 1972). Culture conditions may also affect the subsequent growth of the propagules (Parbery et al 1981) and some organisms may not grow on the medium provided (Baker 1981).

The slides used in the Scotch tape impression method (Langvad 1980) need to be rinsed following staining and spore losses may occur during rinsing. The cellulose nitrate impression films may give similar results as the nail polish films, but it is less con- venient and more time consuming as the film needs to harden for $24 \mathrm{~h}$ (Langvad 1980).

Both plating of the washed leaves onto agar plates and incubating the washed leaves in moist chambers may also allow endophytes to grow. It is, therefore, very difficult to control the length of the incubation period in order to prevent isolation of endophytes as well as phylloplane fungi.

In the leaf impression method, fungal spores on the leaf surface stick onto the agar. This may give rise to very dense fungal and bacterial growth on the agar plate (O. H. K. Lee personal observation) and make isolation of fungi difficult. For the same reason, the tape impression for culturing also results in dense fungal growth. When the spore-fall technique is used, only fungal colonies with mature fruiting bodies will be isolated and immature fungal colonies, or species that need water for spore release, will be neglected.

The aim of the present research is to investigate the abundance and species richness of phylloplane fungi in Hong Kong mangroves. Three methods: direct observation with light microscopy, scanning electron microscopy and the leaf washing method, were compared to study the phylloplane fungi on Kandelia candel and Aegiceras corniculatum which are the most common mangrove trees in Hong Kong.

\section{MATERIALS AND METHODS}

Thirty leaves of Kandelia candel and 30 leaves of Aegiceras corniculatum were collected individually from 60 trees in Sheung Pak Nai $\left(22^{\circ} 27^{\prime} \mathrm{N}, 113^{\circ} 58^{\prime} \mathrm{E}\right)$, New Territories, Hong Kong in the first wk of each mo during the sampling period (sampling for light microscopy and leaf washing method: Jul 1998-Jun 1999; SEM: Jul 1998-Jan 1999). The leaves collected were located $\sim 1 \mathrm{~m}$ above the ground, seldom immersed even during high tide. The size of the sampled leaves of $K$. candel ranged from $\sim 3-5 \mathrm{~cm} \times 5-9 \mathrm{~cm}$, while those of $A$. corniculatum ranged from $\sim 3-5 \mathrm{~cm} \times 4$ $7 \mathrm{~cm}$. Only green, healthy leaves were sampled to ensure only true phylloplane fungi, not pathogens and saprobes, were investigated. To reduce disturbance to the experimental leaves, the petioles and the stems next to these leaves were cut and collected to avoid infection and rapid decay of the leaves after collection.

Direct observation with light microscopy.-Twenty freshly cut leaves, from 10 individual Kandelia candel and 10 from individual Aegiceras corniculatum trees were examined under a dissection microscope (Leica WILD MZ8). The abundance of fungi was scored as estimates of percentage cover per field of view (see Jones 1968, Meese and Tomich 1992, Benedetti-Cecchi et al 1996, for method of percentage cover estimation). Five random fields were taken at $50 \times$ magnification from the upper or the lower surface of each leaf. To investigate variation in fungal abundance between $K$. candel and A. corniculatum, and between the upper and lower leaf surfaces, half of the leaves from the 12 mo sam- 
pling (i.e., $\mathrm{n}=60$ ) were randomly chosen to represent the abundance on the upper surfaces, while the other half represented the lower leaf surfaces. The eyepiece of the microscope was equipped with an ocular grid of 100 squares. Fungal occurrence under the intersection points was recorded. The percentage cover of fungi per leaf was calculated using the following equation:

Percentage cover $=$ number of intersection points containing fungal colonies

in five views

$\div 500 \times 100 \%$

A two-factor analysis of variance (ANOVA) was conducted with mangrove tree species ( $\mathrm{Tr})$ and leaf surfaces $(\mathrm{Su})$ as fixed, orthogonal factors $(\Sigma \mathrm{n}=2$ mangrove species $\times 2$ leaf surfaces $\times 60$ leaves $=240$ ).

Species richness of the phylloplane fungi was also investigated using a stereomicroscope (Olympus BX50). If the fungi could not be picked up with fine forceps, an impression film was made using nail polish. The fungi were observed and identified with the uses of taxonomic keys (Sydow and Sydow 1913, Ellis 1971, 1976, Sutton 1980, Nag Raj 1993, Goh and Yipp 1996, David 1997). The number of fungal species found on the leaves was recorded, and variation in the number of taxa found on the two mangrove species analyzed with a $t$-test.

Scanning electron microscopy.- Twenty leaves were collected from individual Kandelia candel (10 leaves) $(\Sigma \mathrm{n}=10$ leaves $\times 7 \mathrm{mo}=70)$ and Aegiceras corniculatum (10 leaves) $(\Sigma \mathrm{n}=10$ leaves $\times 7 \mathrm{mo}=70)$. A $5.5 \mathrm{~mm}$ diameter disk was randomly cut from each leaf with a sterile hole punch. The leaf disks were then air-dried for one wk before coating with gold/palladium. The disks were then transferred to scanning electron microscope (SEM) stubs, haphazardly with the upper or lower surface face-up. The disks were examined in the SEM at $450 \times$ with a fixed working distance (WD $\sim 17 \mathrm{~mm}$ ). Five random fields of view per disk were photographed. The percentage cover of fungi was estimated by counting the number of fungal parts under 805 intersection points of a transparent plastic grid $(16 \mathrm{~cm} \times 11 \mathrm{~cm})$ superimposed onto the photograph. The mean percentage cover of fungi from the five views was then derived. Fungal abundance, in terms of percentage cover, was compared between the two mangrove species with a Mann-Whitney test as the data did not fulfil assumptions of normality or homogeneity.

Leaf washing method. - Ten leaves from Kandelia candel $(\Sigma$ $\mathrm{n}=10$ leaves $\times 12 \mathrm{mo}=120)$ and 10 from Aegiceras cor niculatum were sampled $(\Sigma \mathrm{n}=10$ leaves $\times 12$ mo $=120)$. Five, 5.5- $\mathrm{mm}$ diameter disks were cut from each leaf, transferred to a conical flask with $50 \mathrm{~mL}$ sterile water and mechanically shaken in a reciprocating shaker at $180 \mathrm{rpm}$ for $20 \mathrm{~min}$. The washed aliquots $(\sim 1 \mathrm{ml}$ per plate $)$ were plated onto malt extract agar (MEA) with mixtures of streptomycin, penicillin and tetracycline in twenty, 9-cm Petri dishes. The plates were incubated at room temperature $(\sim 22 \mathrm{C})$ and repeatedly examined at weekly intervals until no new fungal colonies appeared. Sterile mycelia were sub-cultured to MEA plates with sterile leaf fragments. Fungi were identified using taxonomic keys (Sydow and Sydow 1913, Ellis 1971, 1976, Sutton 1980, Nag Raj 1993, Goh and Yipp 1996, David 1997) when fruiting occurred, and the number of species recorded. The number of fungal taxa found (including sterile mycelia) was square-root transformed (Fowler and Cohen 1990) and compared between the two mangrove species using a $t$-test.

Comparative techniques.-Statistical analyses were conducted to compare the fungal abundance and species richness found using different investigation techniques. Variation in fungal abundance investigated by light microscopy and SEM was tested by a Mann-Whitney test. To compare the difference in number of taxa found by light microscopy and the leaf washing method, the number of taxa was squareroot transformed and compared with a two-factor analysis of variance (ANOVA), with mangrove tree (Tr) and methods $(\mathrm{Me})$ as fixed, orthogonal factors $(\Sigma \mathrm{n}=2$ tree species $\times 2$ methods $\times 12=48$ ).

\section{RESULTS}

Light microscopy.-The mean ( $\pm \mathrm{SE}$ ) total fungal abundance on Kandelia candel and Aegiceras corniculatum was $2.7 \pm 0.5 \%$ and $6.1 \pm 0.9 \%$ respectively. The mean fungal abundance on $K$. candel ranged from $0-7.4 \%$, being nil in Jul and Aug, but reaching a maximum in Nov (FIG. 1). The fungal abundance on A. corniculatum was, however, lowest in Jul, but maximal in Aug 1998, and then decreased in the winter (FIG. 1). It appeared that the abundance of phylloplane fungi on $K$. candel peaked in the transition period between summer and winter, while that on $A$. corniculatum peaked in summer. The abundance of phylloplane fungi on both mangroves species was, however, low in winter (FIG. 1).

Phylloplane fungi were significantly more abundant on the upper than the lower leaf surfaces (TABLE I) and significantly higher on Aegiceras corniculatum leaves than Kandelia candel leaves (TABLE I). There was, however, no interaction between mangrove species and leaf surfaces (TABLE I).

Seven fungal taxa and some unidentified fungal mycelia/hyphae were found with the use of light microscopy (TABLE II). The mean number of fungal taxa found on Kandelia candel was 2.4 per mo, while that of Aegiceras corniculatum was 2.3. Cladosporium species, Pestalotiopsis maculans, and Trimmatostroma species were found all year round on both mangrove species, while Lasiothyrium species and Tubakia-like species were only found in some months (TABLE II). A Tubakia-like species was found on $K$. candel leaves, but not on A. corniculatum leaves. The number of identified fungal taxa found on the two mangrove 


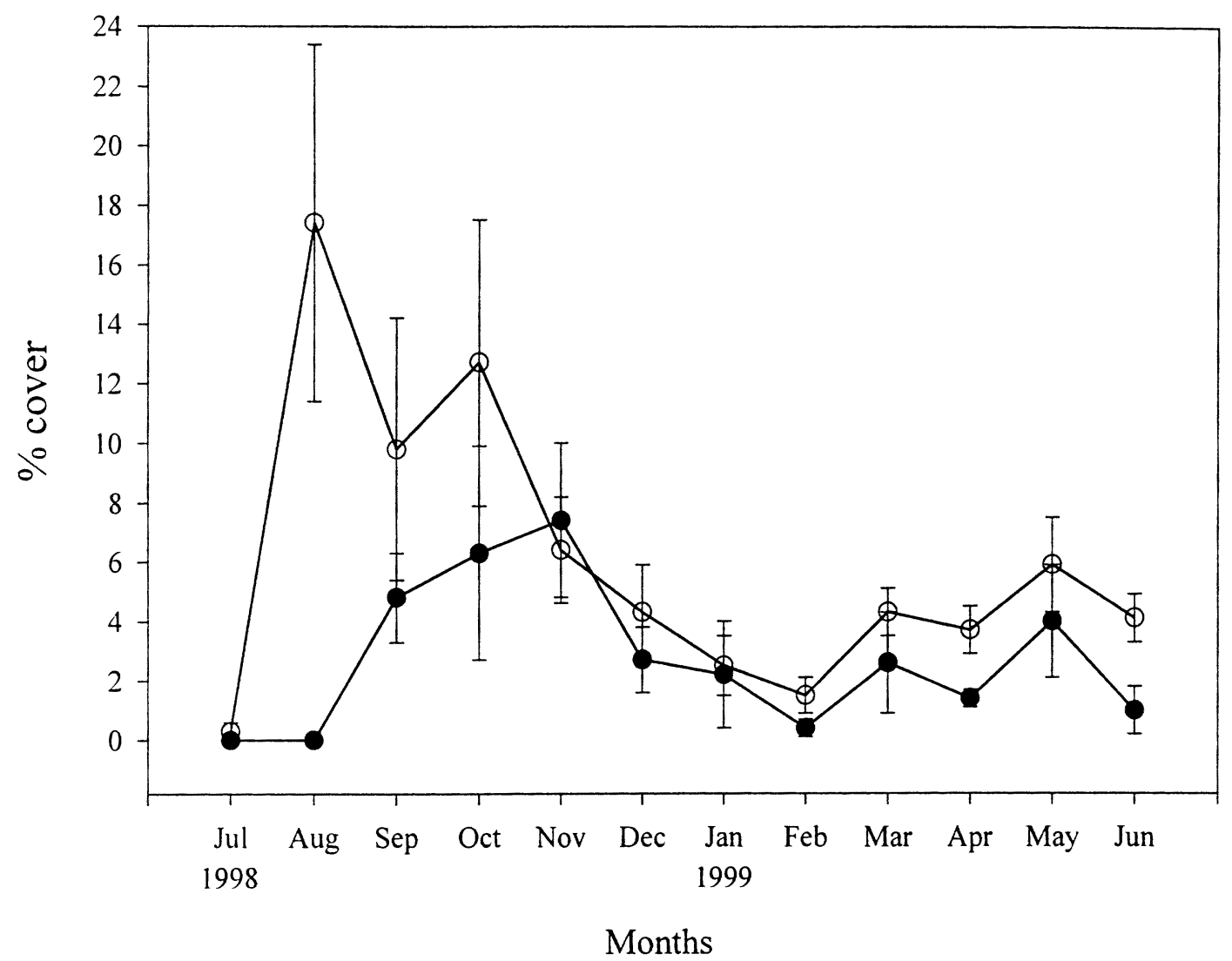

FIG. 1. Mean monthly ( $\pm \mathrm{SE} ; \mathrm{n}=10$ ) total fungal abundance on mangrove leaves as estimated by light microscopy. Black dots $=\%$ cover on Kandelia candel; white dots $=\%$ cover on Aegiceras corniculatum.

species was similar $(t$-test, $t=-0.80, \mathrm{DF}=22, P=$ $0.435)$.

Scanning electron microscopy.-The mean fungal abundance $( \pm \mathrm{SE})$ on Kandelia candel and Aegiceras

TABLE I. Variation in fungal abundance on the upper and lower leaf surfaces (Su) of Kandelia candel and Aegiceras corniculatum (Trees $=\mathrm{Tr} ; \mathrm{n}=60)$. Significant $P$-values $(P$ $<0.05)$ are indicated in bold. Variances were homogenous after arcsine transformation (Cochran's $C=0.35, P>$ $0.05)$. SNK multiple comparison tests were performed for significant results

\begin{tabular}{lrrrrr}
\hline \hline $\begin{array}{l}\text { Source of } \\
\text { variation }\end{array}$ & \multicolumn{1}{c}{ SS } & DF & \multicolumn{1}{c}{ MS } & \multicolumn{1}{c}{$F$} & \multicolumn{1}{c}{$P$} \\
\hline $\mathrm{Tr}$ & 915.93 & 1 & 915.93 & 23.02 & $\mathbf{0 . 0 0 0}$ \\
$\mathrm{Su}$ & 247.74 & 1 & 247.74 & 6.23 & $\mathbf{0 . 0 1 3}$ \\
$\mathrm{Tr} \times \mathrm{Su}$ & 22.34 & 1 & 22.34 & 0.56 & 0.454 \\
$\mathrm{RES}$ & 9389.15 & 236 & 39.78 & & \\
TOT & 10575.16 & 239 & & & \\
SNK tests & & & & & \\
Trees & & & & & \\
$\quad$ Aegiceras corniculatum & $>$ Kandelia candel & \\
Surfaces & & & & & \\
$\quad$ Upper $>$ Lower & & & & \\
\end{tabular}

corniculatum was similar, at $2.6 \pm 0.6 \%$ and $1.7 \pm$ $0.3 \%$ respectively (Mann-Whitney test, $P=0.293$ ). As the abundance of the phylloplane fungi on $K$. candel found by SEM was similar to that of light microscopy (Mann-Whitney test, $P=0.242$ ), investigation of temporal changes of phylloplane fungi by SEM was only conducted for seven mo.

The mean ( \pm SE) fungal abundance found using the SEM ranged from $0.9 \pm 0.4 \%-7.7 \pm 3.4 \%$ on Kandelia candel and $0.3 \pm 0.1 \%-2.9 \pm 1.1 \%$ on Aegiceras corniculatum (FIG. 2). Abundance of phylloplane fungi did not appear to vary in these seven mo, except in Sep 1998 when fungal abundance on $K$. candel increased (FIG. 2).

Leaf washing method.-During the 12 mo sampling, the mean $( \pm \mathrm{SE})$ number of fungal taxa found per mo (including the sterile mycelia) was similar between Kandelia candel and Aegiceras corniculatum $(5.8 \pm 0.7$ and $4.9 \pm 0.5$ respectively; $t$-test, $t=$ $-1.06, \mathrm{DF}=22, P=0.299)$. The number of fungal taxa found on $K$. candel varied during the sampling period, while that of $A$. corniculatum was clearly higher in summer and decreased in winter (FIG. 3).

Thirty fungal cultures sporulated within 20 mo of the experiment, while the other 18 cultures did not 
TABLE II. Identified fungal taxa on Kandelia candel (K) and Aegiceras corniculatum (A) from monthly sampling by light microscopy. $+=$ presence of the taxon

\begin{tabular}{|c|c|c|c|c|c|c|c|c|c|c|}
\hline \multirow[b]{2}{*}{ Fungal taxa } & \multicolumn{2}{|c|}{ Jul } & \multicolumn{2}{|c|}{ Aug } & \multicolumn{2}{|c|}{ Sep } & \multicolumn{2}{|c|}{ Oct } & \multicolumn{2}{|c|}{ Nov } \\
\hline & $\mathrm{K}$ & $\mathrm{A}$ & $\mathrm{K}$ & $\mathrm{A}$ & $\mathrm{K}$ & $\mathrm{A}$ & $\mathrm{K}$ & $\mathrm{A}$ & $\mathrm{K}$ & $\mathrm{A}$ \\
\hline Cladosporium marinum Pal \& Purkayastha & & & + & & + & + & & & & \\
\hline C. oxysporum Berk. \& Curt. & & & & & & & + & + & + & + \\
\hline Lasiothyrium sp. & & & & + & + & + & & + & + & + \\
\hline Pestalotiopsis maculans (Corda) Nag Raj & + & & + & + & + & + & & + & + & \\
\hline $\begin{array}{l}\text { Trimmatostroma botryoforme Goh \& M. W. Yipp } \\
\text { T. sarciniforme Goh \& M. W. Yipp }\end{array}$ & & + & & + & & + & + & & + & + \\
\hline Tubakia-like sp. & & & & & & & + & & & \\
\hline
\end{tabular}

sporulate and were, therefore, classified as Mycelia sterilia (TABLE III). Cladosporium oxysporum and Pestalotiopsis maculans were the most common species, found on both mangrove species all year round. With the exception of Arthrinium sp. and Colletotrichum sp. 2, which were only isolated from $K$. candel, most identified taxa could be found on both hosts. Among the sterile mycelia, Mycelia sterilia 1 and Mycelia sterilia 9 were the most common species (TABLE III).

Comparative techniques.--Estimates of fungal abundance on Kandelia candel were similar using SEM and light microscopy (Mann-Whitney test, $P=0.242$ ), while more fungi were found on A. corniculatum when investigated with light microscopy than with SEM (Mann-Whitney test, $P=0.037$ ). The number of fungal taxa found with the leaf washing method was significantly higher than found using light microscopy (TABLE IV).

\section{DISCUSSION}

Abundance and species richness of phylloplane fungi.The total abundance (i.e., percentage cover on both

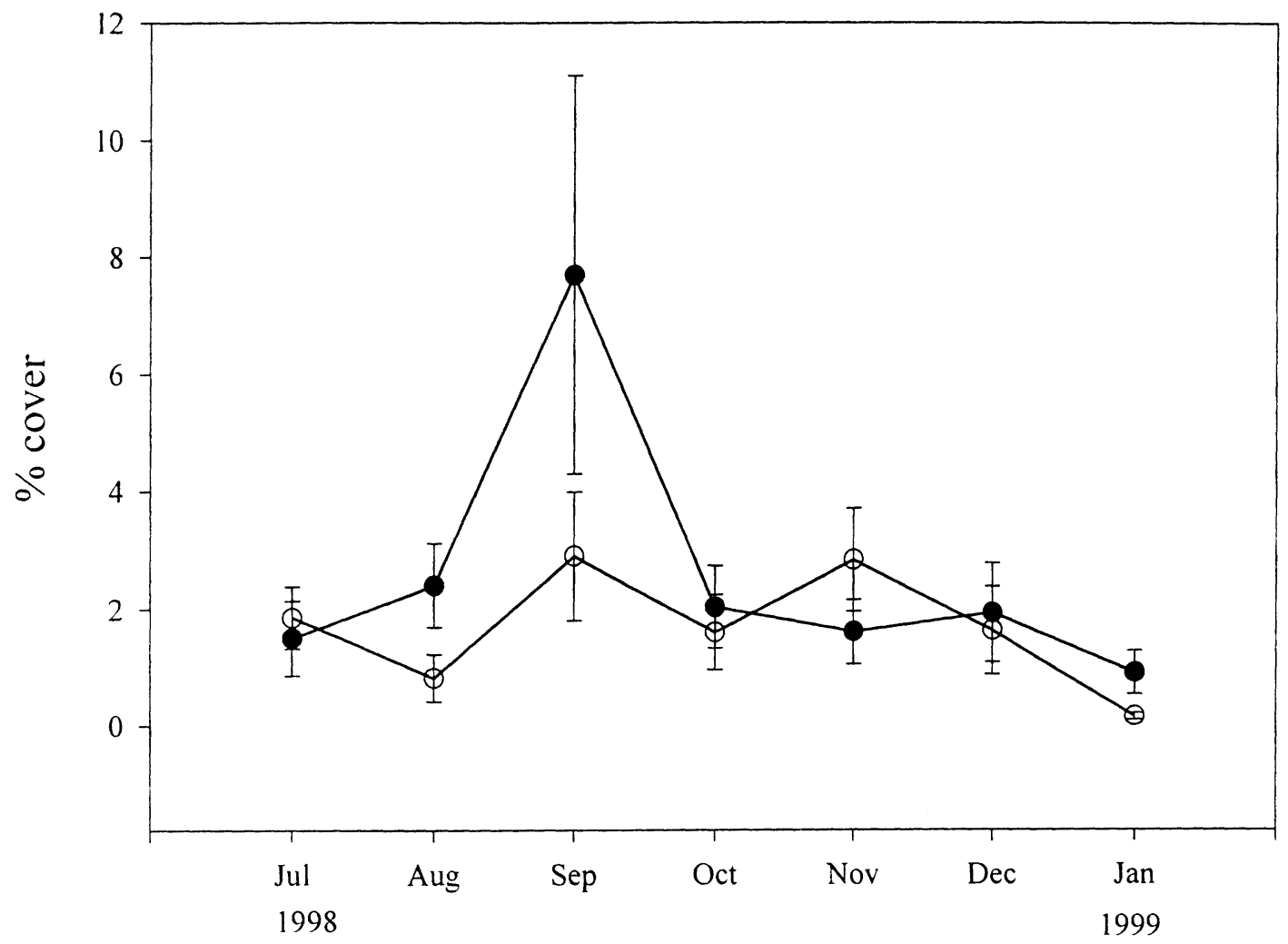

Months

FIG. 2. Mean monthly $( \pm \mathrm{SE} ; \mathrm{n}=10)$ total fungal abundance on mangrove leaves as estimated by SEM. Black dots $=\%$ cover on Kandelia candel; white dots $=\%$ cover on Aegiceras corniculatum. 
TABLE II. Extended

\begin{tabular}{|c|c|c|c|c|c|c|c|c|c|c|c|c|c|}
\hline \multicolumn{2}{|c|}{ Dec } & \multicolumn{2}{|c|}{ Jan } & \multicolumn{2}{|c|}{ Feb } & \multicolumn{2}{|c|}{ Mar } & \multicolumn{2}{|c|}{ Apr } & \multicolumn{2}{|c|}{ May } & \multicolumn{2}{|c|}{ Jun } \\
\hline $\mathrm{K}$ & $\mathrm{A}$ & $\mathrm{K}$ & $\mathrm{A}$ & $\mathrm{K}$ & $\mathrm{A}$ & $\mathrm{K}$ & $\mathrm{A}$ & $\mathrm{K}$ & A & $\mathrm{K}$ & A & $\mathrm{K}$ & $\mathrm{A}$ \\
\hline+ & + & + & & + & & + & + & + & & + & + & + & \\
\hline+ & + & & & & + & & & & & & & + & \\
\hline+ & + & + & + & + & + & + & + & + & + & & + & + & $\begin{array}{l}+ \\
+\end{array}$ \\
\hline
\end{tabular}

the upper and lower leaf surfaces) of phylloplane fungi from Hong Kong mangroves was $<10 \%$. Abundance was relatively low because only green, healthy leaves were studied, thus excluding pathogens and saprobes. The upper surfaces of the leaves had higher fungal abundance than the lower surfaces. A Trimmatostroma species, which was one of the most common taxa found in this study, has previously been found to be associated with the salt glands of Aegiceras corniculatum leaves (Goh and Yipp 1996). As the salt glands are more abundant on the upper leaf surfaces, fungal abundance should, therefore, be higher on these surfaces. Some phylloplane fungi (e.g., Pestalotiopsis species) were abundant on both surfaces of the leaves, as they may be capable of penetrating the epidermis (Kuthubutheen 1984). Some fungi are, however, restricted to the lower leaf surface (Last and Deighton 1965), as the cuticle is thicker on the upper surface (Last and Warren 1972) which may prevent them access to leachates, i.e., nutrients, from the leaves.

Fungal abundance as estimated using scanning electron microscopy (SEM) was similar between the two mangrove species. Light microscopy, however, in-

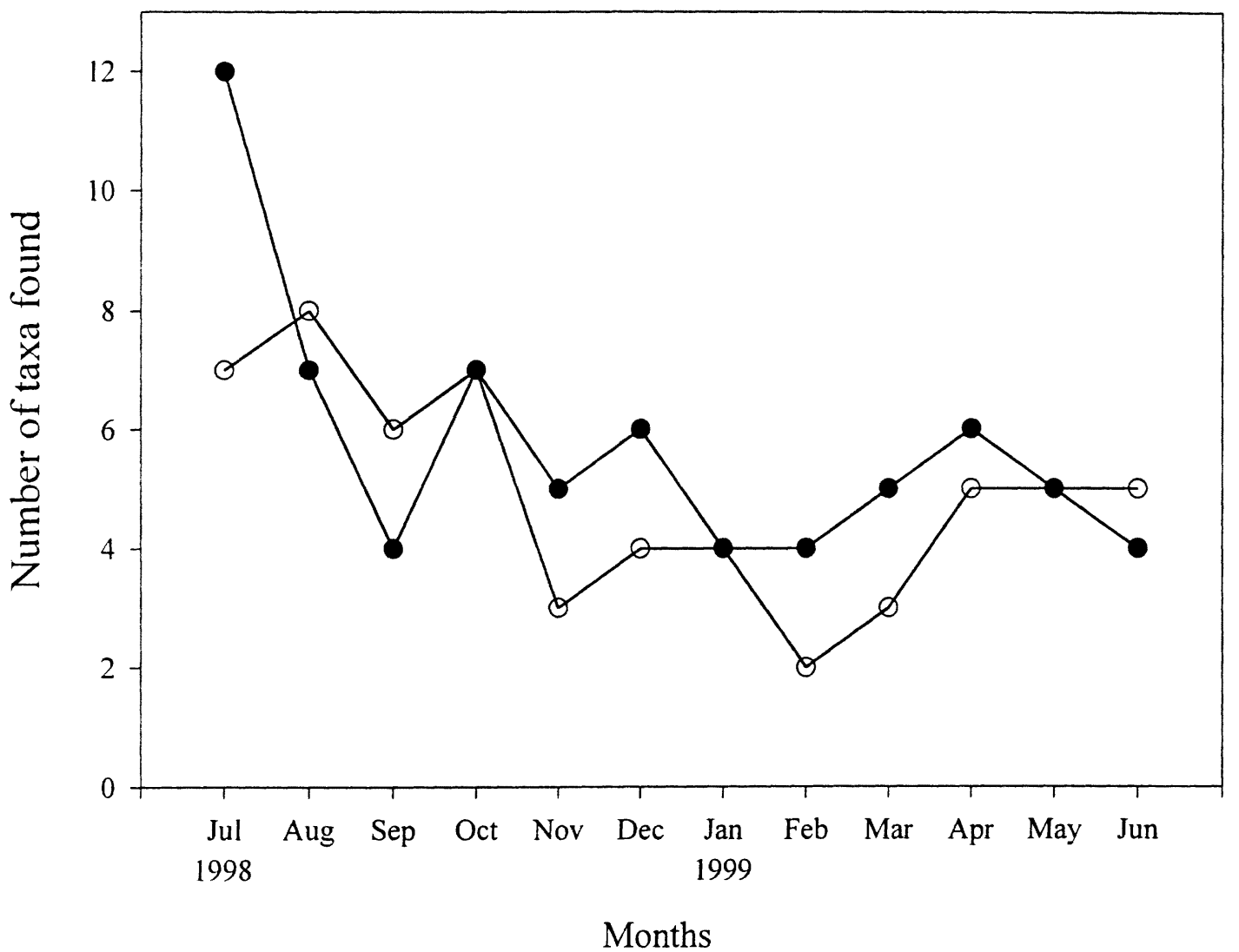

FIG. 3. Number of fungal taxa found per month from the mangroves with the leaf washing method. Black dots = Kandelia candel, white dots = Aegiceras corniculatum. 
TABLE III. Fungal taxa found on Kandelia candel (K) and Aegiceras corniculatum (A) from monthly sampling by the leaf washing method. $+=$ presence of the taxon

\begin{tabular}{|c|c|c|c|c|c|c|c|c|c|c|}
\hline \multirow[b]{2}{*}{ Fungal taxa } & \multicolumn{2}{|c|}{ Jul } & \multicolumn{2}{|c|}{ Aug } & \multicolumn{2}{|c|}{ Sep } & \multicolumn{2}{|c|}{ Oct } & \multicolumn{2}{|c|}{ Nov } \\
\hline & $\mathrm{K}$ & A & $\mathrm{K}$ & A & $\mathrm{K}$ & A & $\mathrm{K}$ & A & $\mathrm{K}$ & A \\
\hline \multicolumn{11}{|l|}{ Acremonium sp. } \\
\hline Arthrinium sp. & & & & & & & + & & & \\
\hline Cladosporium cladosporioides (Fresen.) de Vries & & & & + & + & + & + & + & + & \\
\hline \multicolumn{11}{|l|}{ C. herbarum (Pers.) Link ex S. F. Gray } \\
\hline C. marinum Pal \& Purkayastha & & & + & & & & & & & \\
\hline C. oxysporum Berk. \& Curt. & + & & + & + & & & + & + & + & + \\
\hline \multicolumn{11}{|l|}{ Colletotrichum sp. 1} \\
\hline Colletotrichum sp. 2 & + & & & & & & & & & \\
\hline Memnoniella sp & & & & & + & & & & + & \\
\hline Myrothecium-like sp. & & & & + & & & & & & \\
\hline \multicolumn{11}{|l|}{ Penicillium sp. } \\
\hline Pestalotiopsis maculans (Corda) Nag Raj & + & & + & + & & + & + & + & & + \\
\hline Phoma sp. 1 & + & & & & & + & & & & \\
\hline Phoma sp. 2 & & & & + & + & & & & & \\
\hline Phoma sp. 3 & & & & & & & & & + & \\
\hline Trimmatostroma botryoforme Goh \& M. W. Yipp & & + & & & & & & & & \\
\hline Coelomycete sp. 1 & & & & & & + & & & & \\
\hline \multicolumn{11}{|l|}{ Coelomycete sp. 2} \\
\hline \multicolumn{11}{|l|}{ Coelomycete sp. 3} \\
\hline \multicolumn{11}{|l|}{ Coelomycete sp. 4} \\
\hline \multicolumn{11}{|l|}{ Coelomycete sp. 5} \\
\hline \multicolumn{11}{|l|}{ Coelomycete sp. 6} \\
\hline Hyphomycete sp. 1 & + & + & & & & & & & & \\
\hline Hyphomycete sp. 2 & + & & & & & & & & & \\
\hline Hyphomycete sp. 3 & + & & & & & & & & & \\
\hline Hyphomycete sp. 4 & & & & & & & & + & & \\
\hline \multicolumn{11}{|l|}{ Hyphomycete sp. 5} \\
\hline Unidentified sp. 1 & + & + & & & & & & + & & \\
\hline \multicolumn{11}{|l|}{ Unidentified sp. 2} \\
\hline \multicolumn{11}{|l|}{ Unidentified sp. 3} \\
\hline Mycelia sterilia 1 & + & & + & + & + & & + & & & + \\
\hline \multicolumn{11}{|l|}{ Mycelia sterilia 2} \\
\hline Mycelia sterilia 3 & + & & & & & & & & & \\
\hline Mycelia sterilia 4 & + & & & & & & & & & \\
\hline Mycelia sterilia 5 & & & + & & & & & & & \\
\hline Mycelia sterilia 6 & & & & & & & & + & & \\
\hline Mycelia sterilia 7 & & & & & & & & & & \\
\hline Mycelia sterilia 8 & & + & & + & & & & & & \\
\hline Mycelia sterilia 9 & + & & & & + & + & + & + & & \\
\hline Mycelia sterilia 10 & & & & & & & & & & \\
\hline Mycelia sterilia 11 & & & + & & & & & & & \\
\hline Mycelia sterilia 12 & & & & & & & & & & \\
\hline Mycelia sterilia 13 & & & & & & & & & + & \\
\hline Mycelia sterilia 14 & & + & & & & & & & & \\
\hline Mycelia sterilia 15 & & & & + & & & + & & & \\
\hline Mycelia sterilia 16 & & & + & & & + & & & & \\
\hline Mycelia sterilia 17 & & & & & & & & & & \\
\hline Mycelia sterilia 18 & & & & & & & & & & \\
\hline
\end{tabular}


TABle III. Continued

\begin{tabular}{|c|c|c|c|c|c|c|c|c|c|c|c|c|c|c|}
\hline \multirow[b]{2}{*}{ Fungal taxa } & \multicolumn{2}{|c|}{ Dec } & \multicolumn{2}{|c|}{ Jan } & \multicolumn{2}{|c|}{ Feb } & \multicolumn{2}{|c|}{ Mar } & \multicolumn{2}{|c|}{ Apr } & \multicolumn{2}{|c|}{ May } & \multicolumn{2}{|c|}{ Jun } \\
\hline & $\mathrm{K}$ & A & $\mathrm{K}$ & A & $\mathrm{K}$ & A & $\mathrm{K}$ & A & $\mathrm{K}$ & A & $\mathrm{K}$ & A & $\mathrm{K}$ & A \\
\hline Acremonium sp. & & + & & & & & & & & & & & & \\
\hline Arthrinium sp. & + & & & & & & & & & & & & & \\
\hline Cladosporium cladosporioides (Fresen.) & & & & & & & & & & & & & & \\
\hline de Vries & & & & & & & + & & & + & & & & \\
\hline C. herbarum (Pers.) Link ex S. F. Gray & & & & + & & & & & & & & & & \\
\hline C. marinum Pal \& Purkayastha & & & & & & & & & & & & & & + \\
\hline C. oxysporum Berk. \& Curt. & & + & + & & + & + & & & & + & + & + & + & \\
\hline Colletotrichum sp. 1 & & & & & & & & & + & & & & & \\
\hline Colletotrichum sp. 2 & & & & & & & & & & & + & & & \\
\hline Memnoniella sp & & & & & & & & & & & & & & \\
\hline Myrothecium-like sp. & & & & & & & & & & & & & & \\
\hline Penicillium sp. & & & & & & & & & & & & & & + \\
\hline Pestalotiopsis maculans (Corda) Nag Raj & + & + & + & & + & & & & & + & & + & & \\
\hline Phoma sp. 1 & + & & & & & & & & & & & & & \\
\hline Phoma sp. 2 & & & + & & & & & & & & & & & \\
\hline Phoma sp. 3 & & & & & & & & & & & & & & \\
\hline Trimmatostroma botryoforme Goh \& & & & & & & & & & & & & & & \\
\hline M. W. Yipp & & & & & + & & + & & & & & & & \\
\hline Coelomycete sp. 1 & & & & & & & & & & & & & & \\
\hline Coelomycete sp. 2 & & & & & & & + & & & & & & & \\
\hline Coelomycete sp. 3 & & & & & & & & & + & & & & & \\
\hline Coelomycete sp. 4 & & & & & & & & & & + & & & & \\
\hline Coelomycete sp. 5 & & & & & & & & & & & & & + & \\
\hline Coelomycete sp. 6 & & & & & & & & & & & & & + & \\
\hline Hyphomycete sp. 1 & & & & & & & & & & & & & & \\
\hline Hyphomycete sp. 2 & & & & & & & & & & & & & & \\
\hline Hyphomycete sp. 3 & & & & & & & & & & & & & & \\
\hline Hyphomycete sp. 4 & & & & & & & & & & & & & & \\
\hline Hyphomycete sp. 5 & & & & & & & & & & & & & & + \\
\hline Unidentified sp. 1 & & & & & & & & & & & + & & & \\
\hline Unidentified sp. 2 & + & & & & & & & & & & & & & \\
\hline Unidentified sp. 3 & & & & & & & & & & & & & & + \\
\hline Mycelia sterilia 1 & & & & + & & + & + & + & & & & & & \\
\hline Mycelia sterilia 2 & & & & & & & & & & & + & & & \\
\hline Mycelia sterilia 3 & & & & & & & & & + & & + & + & & \\
\hline Mycelia sterilia 4 & & & & & & & & & + & & & & & \\
\hline Mycelia sterilia 5 & & & + & & & & & & & & & + & & \\
\hline Mycelia sterilia 6 & & & & & & & & & & & & & & \\
\hline Mycelia sterilia 7 & & & & & & & & & + & & & & & \\
\hline Mycelia sterilia 8 & & & & & & & & & & & & & & \\
\hline Mycelia sterilia 9 & + & & & & & & + & + & & & & & & \\
\hline Mycelia sterilia 10 & & & & & & & & & & & & + & & \\
\hline Mycelia sterilia 11 & & + & & & & & + & & & & & & & \\
\hline Mycelia sterilia 12 & & & & & & & & & + & & & & & \\
\hline Mycelia sterilia 13 & + & & & & & & & & & & & & & \\
\hline Mycelia sterilia 14 & & & & & & & & & & & & & & \\
\hline Mycelia sterilia 15 & & & & & & & & & & + & & & & \\
\hline Mycelia sterilia 16 & & + & & & & & & & & & & & & \\
\hline Mycelia sterilia 17 & & & & + & & & & & & & & & & + \\
\hline Mycelia sterilia 18 & & & & & + & & & & & & & & & \\
\hline
\end{tabular}


TABLE IV. Variation in number of fungal taxa found on Kandelia candel and Aegiceras corniculatum (Tr) using leaf washing and light microscopy (Methods $=$ Me; $\mathrm{n}=12$ ). Significant $P$-values $(P<0.05)$ are indicated in bold. Variances were homogenous after square-root transformation (Cochran's $C=0.34, P>0.05$ ). SNK multiple comparison tests were performed for significant results

\begin{tabular}{lcrrrr}
\hline $\begin{array}{l}\text { Source of } \\
\text { variation }\end{array}$ & \multicolumn{1}{c}{ SS } & DF & MS & \multicolumn{1}{c}{$F$} & $P$ \\
\hline $\mathrm{Tr}$ & 0.16 & 1 & 0.16 & 1.46 & 0.233 \\
$\mathrm{Me}$ & 5.38 & 1 & 5.38 & 47.73 & $\mathbf{0 . 0 0 0}$ \\
$\mathrm{Tr} \times \mathrm{Me}$ & 0.03 & 1 & 0.03 & 0.25 & 0.618 \\
$\mathrm{RES}$ & 4.96 & 44 & 0.11 & & \\
$\mathrm{TOT}$ & 10.53 & 47 & & & \\
SNK tests & & & & \\
Methods & & & \\
\multicolumn{7}{l}{ Leaf washing method $>$ Light microscopy } \\
\hline
\end{tabular}

dicated that fungal abundance was higher on Aegiceras corniculatum than Kandelia candel. The number of taxa and species found on the two mangrove species were, however, similar.

Phylloplane communities may be similar on different plants, such as mangrove plants and terrestrial, non-maritime plants (Kuthubutheen 1981, 1984). Phylloplane fungi found on a terrestrial tree, Eucalyptus viminalis, included Cladosporium cladosporioides, Penicillium species, Phoma sp., Pestalotiopsis oxyanthi, Arthrinium species, and Colletotrichum species (Cabral 1985). These genera have also been found on other plant species including those from mangroves (Kuthubutheen 1981, 1984, this study), although they may not be the same species.

Seven fungal taxa were found using light microscopy. The most common species were Cladosporium oxysporum, Pestalotiopsis maculans, and Trimmatostroma botryoforme. Cladosporium oxysporum is common in the tropics, usually being found on dead parts of leaves and stems of herbaceous and woody plants (Ellis 1971). It has been consistently recorded on the leaves of all mangrove trees sampled in Malaysia by Kuthubutheen (1981). Pestalotiopsis maculans has been found on the living leaves of terrestrial plants and was reported as a pathogen (Nag Raj 1993). Trimmatostroma botryoforme has previously been recorded on the leaf surfaces of Aegiceras corniculatum in Hong Kong mangroves (Goh and Yipp 1996).

A combination of three investigation methods (i.e., light microscopy, SEM, and a leaf washing method) showed that Cladosporium species and Pestalotiopsis maculans were the most common species in Hong Kong mangroves and were present all year round. These species are capable of growth on the leaf surfaces of mangroves (Kuthubutheen 1984, but see Last and Deighton 1965). Cladosporium cladosporioides, which was commonly isolated using the leaf washing method, is a weak pathogen and is common on the aerial surfaces of many higher plants throughout temperate regions. This species has darkly-pigmented, thick-walled hyphae which may enable the fungi to withstand excessive radiation and heat (Ellis 1971, Dickinson 1981). It is also an endophyte (Cabral 1985) and increases colonization on aging and yellowing leaves (Last and Deighton 1965). Pestalotiopsis species, Penicillium species, and Cladosporium oxysporum occur throughout the development and growth of leaves (Kuthubutheen 1981). Trimmatostroma spp., which were commonly found using light microscopy, were dominant on A. corniculatum at another Hong Kong mangrove, Ting Kok (Goh and Yipp 1996). This genus is a non-parasitic associate and was stated to be host specific at Ting Kok (Goh and Yipp 1996), but was also found on K. candel in the present study.

Seasonal variation of phylloplane fungi.-The abundance of phylloplane fungi exhibited temporal variation in the present study when investigated by light microscopy. Fungal abundance on Kandelia candel increased in late summer and was highest in the transition period between summer and winter (see Kaehler and Williams 1996 for description of seasons), while that on Aegiceras corniculatum peaked in Aug and decreased in winter. When investigated with the SEM, the pattern of fungal abundance on $K$. candel was similar to that seen using light microscopy. The number of fungal taxa found on $K$. candel showed no temporal variation, while on $A$. corniculatum the number of taxa increased in summer, but decreased in winter. Hong Kong has a hot, wet summer, but cool, dry winter (Morton and Morton 1983, Kaehler and Williams 1996). As wetness is an important factor in facilitating fungal growth (Ruinen 1961), the relatively dry environment may account for the low phylloplane fungal abundance in winter. A distinct seasonal pattern was reported for phylloplane fungi on Eucalyptus viminalis in Argentina, with maximum abundance in the autumn-winter and minimum in the summer (Cabral 1985). The airborne spore concentration of many phylloplane fungi is subject to seasonal change (Last and Warren 1972).

Dispersal of phylloplane species is largely passive and may be affected by rain-wash or other vectors (Andrews and Kinkel 1986). Cladosporium cladosporioides, for example, produces a large amount of wind-dispersed conidia in summer (Dickinson 1981). Rain and wetness of the leaf surface affect the development of fungi (Ruinen 1961, Reuveni and Rotem 1974, Wheeler 1981), as germination and growth of 
germ tubes are facilitated in high humidity (Dickinson 1981, 1986, Cabral 1985). Fungal abundance and species richness, thus, are higher in summer. High temperature, however, might reduce the growth of fungi (Cabral 1985, Dickinson 1986). Some phylloplane fungi (e.g., Lasiothyrium species) produce spores in the cooler months only, although Trimmatostroma species form spores all year round (Goh and Yipp 1996). Several phylloplane, filamentous fungi (e.g., Cladosporium species) are able to form chlamydospores and sclerotia in unfavorable environments (Dickinson 1986). Phylloplane fungi are, therefore, able to grow immediately in favorable conditions, i.e., in the warm and wet summer.

Methods to study phylloplane fungi.-The leaf washing method resulted in a higher number of taxa (48) than using light microscopy (7). Leaf washing probably overestimates species richness since many casuals might grow on the agar plate (Norse 1972). It has been suggested that species isolated with a high frequency by leaf washings can be considered as true inhabitants of the phylloplane (Cabral 1985). Cladosporium cladosporioides, C. oxysporum, and Pestalotiopsis maculans could be considered as true phylloplane fungi as they were commonly found on many leaf specimens of the two mangrove species throughout the year. Other fungal species found using light microscopy might also be true phylloplane fungi as they occurred continuously during the sampling period, and thus may able to grow on the leaf surfaces.

Many fungal taxa found by the leaf washing method might be casuals (Norse 1972), as the taxa growth on the agar plates might be from dormant spores from the leaf surfaces. Cladosporium and Colletotrichum species, for example, are considered as cosmopolitan pathogens (Ellis 1971, Sutton 1980). They might not, therefore, actively grow on healthy leaves. Phoma species might also be saprobes (Sutton 1980). The leaf washing method cannot, however, provide a quantitative description of the species richness of the phylloplane fungi as leaf washings only indicate the amount of propagules, but not the fungal biomass (Mendgen 1986). The large amount of Mycelia sterilia species recorded with the use of the leaf washing method might also overlook some common species as these species might not sporulate ex situ. Trimmatostroma species and a Tubakia-like species, which were commonly found by light microscopy, were not found by the leaf washing method and did not sporulate in culture.

The number of fungal taxa found with the leaf washing method was similar to some previous studies (Kuthubutheen 1981, 1984). These studies might, however, include some endophytes, as they also re- corded the fungi found on the washed leaves. Fungal taxa found in this study were also different from a study of Aegiceras corniculatum in India (Sivakumar and Kathiresan 1990), perhaps due to the variation in technique as a leaf impression method was used in the Indian study. Both of these previous studies (Kuthubutheen 1981, 1984, Sivakumar and Kathiresan 1990) are likely to only reveal the casuals, but not the true phylloplane fungi from the mangroves.

Fungal abundance found by light microscopy was similar to that by SEM. It was not, however, possible to identify the phylloplane fungi to species level with the SEM. The preparation time of specimens for SEM is longer than for light microscopy and the running cost of the SEM is high. Direct observation using the light microscope is, therefore, the most suitable method for studying the abundance and species richness of true phylloplane fungi, while the leaf washing method is suitable for qualitative studies only.

\section{ACKNOWLEDGMENTS}

Dr. Gray A. Williams of the Department of Ecology \& Biodiversity, The University of Hong Kong, is thanked for comment on the experimental design and the manuscript. Ms Helen Leung (DEB) and Mr. W. S. Lee of Electron Microscope Unit, HKU, are thanked for technical support. O. H. $\mathrm{K}$. Lee acknowledges The University of Hong Kong for the award of a Postgraduate Studentship.

\section{LITERATURE CITED}

Andrews JH, Kinkel LL. 1986. Colonization dynamics: the island theory. In: Fokkema NJ, Heuvel JVD, eds. Microbiology of the phyllosphere. Cambridge: Cambridge University Press. p 63-76.

Bainbridge A, Dickinson CH. 1972. Effect of fungicides on the microflora of potato leaves. Trans Br Mycol Soc 59: $31-41$.

Baker JH. 1981. Direct observation and enumeration of microbes on plant surfaces by light microscopy. In: Blakeman JP, ed. Microbial ecology of the phylloplane. London: Academic Press. p 3-14.

Benedetti-Cecchi L, Airoldi L, Abbiati M, Cinelli F. 1996. Estimating the abundance of benthic invertebrates: a comparison of procedures and variability between observers. Mar Ecol Prog Ser 138:93-101.

Cabral D. 1985. Phyllosphere of Eucalyptus viminalis: dynamics of fungal populations. Trans Br Mycol Soc 85: 501-511.

Carris LM. 1992. Vaccinium fungi: Pseudotracylla falcata sp. nov. Mycologia 84:534-540.

Cunningham JL. 1972. A miracle mounting fluid for permanent whole-mounts of microfungi. Mycologia 64: 906-910.

David JC. 1997. A contribution to the systematics of Clado- 
sporium: revision of the fungi previously referred to Heterosporium. Oxon: CAB International. 157 p.

Dickinson CH. 1967. Fungal colonization of Pisum leaves. Can J Bot 45:915-927.

- 1973. Effects of ethirimol and zineb on phylloplane microflora of barley. Trans Br Mycol Soc 60:423-431.

- 1981. Biology of Alternaria alternata, Cladosporium cladosporioides and C. herbarum in respect of their activity on green plants. In: Blakeman JP, ed. Microbial ecology of the phylloplane. London: Academic Press. p 169-184.

- 1986. Adaptations of micro-organisms to climatic conditions affecting aerial plant surfaces. In: Fokkema NJ, Heuvel JVD, eds. Microbiology of the phyllosphere. Cambridge: Cambridge University Press. p 77-100.

, Watson J, Wallace B. 1974. An impression method for examining epiphytic micro-organisms and its application to phylloplane studies. Trans Br Mycol Soc 63: 616-619.

Ellis MB. 1971. Dematiaceous hyphomycetes. 1st ed. Oxon: CAB International. 608 p.

1976. More dematiaceous hyphomycetes. 1st ed. Oxon: CAB International. 507 p.

Fowler J, Cohen L. 1990. Practical statistics for field biology. 1st ed. Milton Keynes: Open University Press. 227 p.

Godfrey BES. 1974. Phylloplane mycoflora of bracken, Pteridium aquilinum. Trans Br Mycol Soc 62:305-311.

Goh TK, Yipp MW. 1996. In vivo and in vitro studies of three new species of Trimmatostroma associated with sooty spots of the mangrove Aegiceras corniculatum in Hong Kong. Mycol Res 100:1489-1497.

Hislop EC, Cox TW. 1969. Effects of captan on the nonparasitic microflora of apple leaves. Trans Br Mycol Soc 52:223-235.

Jones RS. 1968. A suggested method for quantifying gut contents in herbivorous fishes. Micronesica 4:369-371.

Kaehler S, Williams GA. 1996. Distribution of algae on tropical rocky shores: spatial and temporal patterns of noncoralline encrusting algae in Hong Kong. Mar Biol 125: 177-187.

Kuthubutheen AJ. 1981. Fungi associated with the aerial parts of Malaysian mangrove plants. Mycopathologia 76:33-43.

-1984. Leaf surface fungi associated with Avicennia alba and Rhizophora mucronata in Malaysia. In: Proceedings of the Asian symposium on mangrove environment-research and management, Kuala Lumpur, 25-29 August 1984. p 153-171.

Lamb RJ, Brown JF. 1970. Non-parasitic microflora on leaf surfaces of Paspalum dilatatum, Salix babylonica and Eucalyptus stellulata. Trans Br Mycol Soc 55:383-390.

Langvad F. 1980. A simple and rapid method for qualitative and quantitative study of the fungal flora of leaves. Can J Bot 26:666-670.

Last FT, Deighton FC. 1965. The non-parasitic microflora on the surfaces of living leaves. Trans Br Mycol Soc 48: 83-99.

—, Warren RC. 1972. Non-parasitic microbes coloniz- ing green leaves: their form and functions. Endeavour 31:143-150.

Leben C. 1965. Epiphytic micro-organisms in relation to plant diseases. Annu Rev Phytopathol 2:209-230.

Lindsey BI. 1976. A survey of methods used in the study of microfungal succession on leaf surfaces. In: Dickinson $\mathrm{CH}$, Preece TF, eds. Microbiology of aerial plant surfaces. London: Academic Press. p 217-222.

Meese RJ, Tomich PA. 1992. Dots on the rocks: a comparison of percent cover estimation methods. J Exp Mar Biol Ecol 165:59-73.

Mendgen K. 1986. Quantitative serological estimations of fungal colonization. In: Fokkema NJ, Heuvel JVD, eds. Microbiology of the phyllosphere. Cambridge: Cambridge University Press. p 50-59.

Mishra RR, Dickinson CH. 1981. Phylloplane and litter fungi of Ilex aquifolium. Trans Br Mycol Soc 77:329-337.

Morton B, Morton J. 1983. The sea shore ecology of Hong Kong. Hong Kong: Hong Kong University Press. 350 p.

Nag Raj TR. 1993. Coelomycetous anamorphs with appendage-bearing conidia. 1st ed. Ontario: Mycologue Publications. $1101 \mathrm{p}$.

Norse D. 1972. Fungal populations of tobacco leaves and their effect on the growth of Alternaria longipes. Trans Br Mycol Soc 59:261-271.

Parbery JH, Brown JF, Bofinger VJ. 1981. Statistical methods in the analysis of phylloplane populations. In: Blakeman JP, ed. Microbial ecology of the phylloplane. London: Academic Press. p 47-65.

Paton AM. 1982. Light microscope techniques for the microbiological examination of plant materials. In: Rhodes-Roberts ME, Skinner FA, eds. Bacteria and plants. London: Academic Press. p 235-243.

Pugh GJF, Mulder JL. 1971. Mycoflora associated with Typha latifolia. Trans Br Mycol Soc 57:273-282.

—, Williams GM. 1968. Fungi associated with Salsola kali. Trans $\mathrm{Br}$ Mycol Soc 51:389-396.

Reuveni R, Rotem J. 1974. Effect of humidity on epidemiological patterns of the powdery mildew (Sphaerotheca fuliginea) on squash. Phytoparasitica 2:25-33.

Ruinen J. 1961. The phyllosphere I. an ecologically neglected milieu. Plant Soil 15:81-109.

Ruscoe QW. 1971. Mycoflora of living and dead leaves of Nothofagus truncata. Trans Br Mycol Soc 56:463-474.

Sivakumar A, Kathiresan K. 1990. Phylloplane fungi from mangroves. Indian J Microbiol 30:229-231.

Sutton BC. 1980. The coelomycetes: fungi imperfecti with pycnidia, acervuli and stromata. 1st ed. U.K.: Commonwealth Mycological Institute. $696 \mathrm{p}$.

Sydow H, Sydow P. 1913. Enumeration of Philippine fungi with notes and descriptions of new species, II. Philipp j sci, C Botany 8:505.

Vardavakis E. 1988. Seasonal fluctuation of non-parasitic mycoflora associated with leaves of Cistus incanus, Arbutus unedo and Quercus coccifera. Mycologia 80:200210.

Wheeler BEJ. 1981. Biology of powdery mildews on leaf surfaces. In: Blakeman JP, ed. Microbial ecology of the phylloplane. London: Academic Press. p 69-84. 